\title{
An extended fuzzy TOPSIS-GRA method based on different separation measures for green logistics service provider selection
}

\author{
E. Celik ${ }^{1}$ M. $\operatorname{Erdogan}^{2}$ A. T. Gumus ${ }^{2}$
}

Received: 4 October 2012/Revised: 11 November 2015/Accepted: 8 March 2016/Published online: 4 April 2016

(C) Islamic Azad University (IAU) 2016

\begin{abstract}
In this paper, first, the criteria that make logistics service providers more "green" are determined as: cooperation with customer's company and its customer, green government regulations, environmental management system, green process design, reduction in energy consumption and green network design. The criteria weights are determined by fuzzy AHP, based on expert opinions. Then, a new method is proposed, which is the combination of fuzzy TOPSIS and GRA, and used to evaluate green 3PLs based on different separation measures, as an extension, using trapezoidal fuzzy numbers. Five Turkish 3PLs serve in Istanbul are selected in order to apply a case study to show the applicability of the proposed method. Finally, the proposed method is verified with respect to different resolving coefficient values and separation measures and also compared with fuzzy TOPSIS and fuzzy VIKOR method results. Different multi-criteria decision-making methods can be applied and compared to check validity of our results for future studies. The proposed method can also be implemented to 3PLs in other countries.
\end{abstract}

Keywords Fuzzy GRA · Fuzzy TOPSIS · Green logistics · Logistics service provider selection · Trapezoidal fuzzy numbers

E. Celik

erkancelik@tunceli.edu.tr

1 Department of Industrial Engineering, Tunceli University, 62000 Tunceli, Turkey

2 Department of Industrial Engineering, Yildiz Technical University, 34349 Besiktas, Istanbul, Turkey

\section{Introduction}

Increased environmental pollution is forcing companies to become more environmentally friendly. Companies that produce logistics services should obtain sensitivity to environmental awareness and environmentally friendly policies. Third-party logistics service providers (3PLs) play a major role between outsourcing companies, market and customers (Liu and Wang 2009). The 3PLs include using external companies to perform logistics functions, which have been traditionally operational within an organization (Liu and Wang 2009; Işıklar et al. 2007). The main advantages of 3PLs can be ranged as let to customer firms to concentrate on the core competencies improve the service, reduce the transportation cost, restructure the supply chains and establish the marketplace legitimacy (Bhatnagar et al. 1999). In the competitive business world, usage of 3PLs by the companies that put to use recycling, reuse and remanufacturing functions, has valuable effects on their performances (Govindan et al. 2012). In the use of logistics outsourcing, 3PL selection and evaluation is a critical process; by selecting the right 3PL, customer companies can reduce capital investments in facilities, equipment, information technology and manpower, increase the flexibility in adapting to changes in the market, reduce inventory and improve inventory turnover rate, improve on-time delivery, reduce transportation cost (Liu and Wang 2009; Ho et al. 2012; Razzaque and Sheng 1998). Selection of the best 3PL requires more than scanning price lists; it also depends on many factors both quantitative and qualitative. Many multi-criteria decision-making methods, such as analytic hierarchy process (AHP), analytic network process (ANP), artificial neural networks (ANN), case-based reasoning (CBR), data envelopment analysis (DEA), rulebased reasoning (RBR) and technique for order preference 
by similarity to ideal solution (TOPSIS), are used for selection of 3PLs (Ho et al. 2012).

In this paper, first, the criteria that make 3PLs more "green" are determined as: cooperation with customer company and its customer, green government regulations, environmental management system, green process design, reduction in energy consumption and green network design. The criteria weights are determined by fuzzy AHP, based on expert opinions. Then, a combined fuzzy TOPSIS-GRA (grey relational analysis) method is proposed to evaluate green 3PLs based on different separation measures for trapezoidal fuzzy numbers. Five Turkish 3PLs serve in Istanbul are selected in order to apply a case study to show the applicability of the proposed method. The proposed method is verified with respect to different resolving coefficient values and separation measures and also compared with fuzzy TOPSIS and fuzzy VIKOR method results.

The rest of paper is organized as follows: In "Literature review" section, a detailed literature review is presented about green logistics, green applications of 3PLs and selection of green 3PLs. "Materials and methods" section gives brief literatures and computations of fuzzy TOPSIS and GRA methods. "The proposed combined fuzzy TOPSIS and GRA method" section describes the proposed method combining fuzzy TOPSIS and GRA, to evaluate green 3PLs. In "Results and discussion" section, a case study considering five 3PL companies and consequently verification of the proposed method are presented. Finally, "Conclusion" section concludes our study.

\section{Literature review}

In this section, the literature background of green logistics, green applications of 3PLs and selection of green 3PLs is presented.

\section{Green logistics}

Greening has become a key word for environmental concerns. When "logistics" term is put next to "green", it becomes an environmentally friendly and efficient transport and distribution system (Rodrigue et al. 2001). Green logistics is an entire part of production logistics applications to increase green degree and also includes green packaging and reverse logistics (Ying and Li-Junb 2008). Whilst the traditional logistics provides the flow of forward activities from supplier to consumer, environmental concerns cause to arise a new concept "reverse logistics" by taking into consideration waste management, recycling, etc. (Erdogan and Gumus 2012).
Lai and Christina (2012) describe green logistics as a management approach that considers product return and recycling, environmental management systems and ecoefficiency as viable ways to comply with environmentbased regulations in international trade. Green logistics management provides resource conservation, waste reduction and organizational skills to meet social expectations for environmental protection (Lai and Christina 2012; Ramanathan and Yunfeng 2009). Evangelista et al. (2011) conduct a detailed literature survey suggesting methods to be more "green" for companies on their transportation and logistics activities. They list the studies as: modal changes and intermodal solutions (McKinnon 2010a), advances in technology solutions (McKinnon 2010b), tools for assessing logistics carbon footprint (Eglese and Black 2010; Lieb and Lieb 2010; McKinnon 2010c), green transport management (Lieb and Lieb 2010) and green logistics system design (Erdogan and Gumus 2012; Harris et al. 2010).

\section{Green applications of 3PLs}

For the physically distribution companies, outsourcing logistics activities has become an integral part of supply chain management (Ageron et al. 2011). 3PLs are put into strategic role because of growing interest in logistics services. Many researches claim that if logistics firms do not measure company performance and monitor it in a flow of functions rather than individual activities, supply chain will not be operative (Robertson et al. 2002). 3PLs provide integrated logistics services and are closely related to supply chain management (Tezuka 2011). The value-added services provided by 3PLs can be ranged as repair, remanufacturing, re-packaging and re-labelling (Min and Ko 2008).

The 3PLs have a critical position in improving environmental sustainability of supply chain operations (Azadi and Saen 2011). In Hamdan and Roger's (2008) study, DEA is used to evaluate warehouse logistics operations of a group of 3PLs. They determine the impact of each input and output on the efficiency of each warehouse, studied on specific warehouse characteristics and made suggestions for improvement and design of more efficient operations. Evangelista et al. (2011) present a guideline for buyers to consider their awareness, initiatives as well as drivers and barriers affecting 3PLs' sustainability initiatives.

Azadi and Saen (2011) use DEA to select third-party reverse logistics providers (3PRLPs). The relationship between 3PLs and environmental consciousness is investigated in Tezuka's (2011) study. He analyses the environmental issues from the point of economy and names this as "externality" problem. Krumwiede and Sheu (2002) 
develop a reverse logistics decision-making model for strategic reverse logistics decision-making. Kuo et al. (2015) present a framework of the supplier evaluating process for carbon management by integrating fuzzy ANP and fuzzy TOPSIS approaches. Govindan et al. (2012) describe a case study considering a company in the tire industry aiming to show how a 3PRLP may be chosen as a partner from $n$ possible provider alternatives. Min and Ko (2008) propose a dynamic reverse logistics model for 3PLs. Here, a mixed-integer programming model and a genetic algorithm are used for the location and allocation of repair facilities for 3PLs.

\section{Selection of green logistics service providers}

There are lots of studies in the literature about selecting the right 3PLs, but nowadays companies are looking for green 3PLs for improving the environmental sustainability. Rational selection of green 3PLs gives companies the advantage of professionalism and takes the advantage of cost to achieve the goals as logistics routing optimization (Shan 2012). There are limited numbers of studies in the literature related to green 3PLs. The studies are usually concerned with the selection of 3PLs. Jharkharia and Shankar (2007) focus on the issues concerning evaluation and selections of providers. Kannan et al. (2009) develop a multi-criteria group decision-making model based on fuzzy TOPSIS in fuzzy environment to guide the selection process of best 3PRLP. Aghazadeh (2003) determine the most effective ways of choosing 3PLs. Azadi and Saen (2011) propose the approach of a new chance-constrained DEA (CCDEA) to assist the decision-makers to determine the most appropriate 3PRLPs in the presence of both dual-role factors and stochastic data. Ho et al. (2012) develop an integrated approach, combining quality function deployment (QFD), fuzzy set theory and AHP approach, to evaluate and select the optimal 3PLs in their study.

Lee et al. (2009) determine criteria and sub-criteria for evaluating traditional and green suppliers. They propose a model to evaluate green suppliers or to select the best green supplier for cooperation. Buyukozkan and Ciftci (2012) use a novel hybrid MCDM approach based on fuzzy DEMATEL, fuzzy ANP and fuzzy TOPSIS to evaluate green suppliers for the need of improving green supply chain management initiatives. According to their references, there are the five major evaluation criteria for green suppliers, and these are listed as organization, financial performance, service quality, technology and green competencies (Awasthi et al. 2010; Humphreys et al. 2003; Kuo et al. 2010; Lee et al. 2009; Walker et al. 2008). Tuzkaya et al. (2009) present a methodology for the evaluation of suppliers' environmental performances. Yang and $\mathrm{Wu}$ (2007) present a research using grey entropy method for green supplier selection. Humphreys et al. (2003) present a framework for integrating environmental factors into the supplier selection process. Kuo et al. (2010) develop a green supplier selection model that integrates ANN and two multi-attribute decision analysis methods: DEA and ANP. Amindoust et al. (2012) present a study for a ranking model based on fuzzy inference system for sustainable supplier selection. Walton et al. (1998) propose a number of supply chain environmentally friendly practices (EFP) and define their top ten environmental supplier evaluation criteria. Buyukozkan (2012) presents a decision model for supplier performance evaluation by considering various environmental performance criteria. One of the rare publications using GRA for green supplier evaluation is Tseng's (2010) paper. His study attempts to develop the fuzzy GRA to rank the best supplier prior to environmental knowledge management capacities. Fu et al. (2012) introduce a formal structured managerial approach for organizations to help evaluating the influence relationships amongst green supplier development programs using a formalized grey-based DEMATEL methodology.

\section{Materials and methods}

\section{The fuzzy TOPSIS and GRA methods}

Here, brief literatures and computations of fuzzy TOPSIS and GRA methods are presented.

\section{Fuzzy TOPSIS}

TOPSIS, one of the classical MCDM methods, was proposed by Hwang and Yoon (1992). TOPSIS is based on the concept that the chosen alternative should have the shortest distance from the positive ideal solution (PIS) and the farthest from the negative ideal solution (NIS) for solving a multiple criteria decision-making problem. Chen and Hwang (1992) applied fuzzy numbers to establish fuzzy TOPSIS.

The algorithm and the steps of the fuzzy TOPSIS method are given below (Chen 2000):

Step 1 In the first step, assume that a decision group has $K$ people, and then, the importance of the criteria and the rating of alternatives with respect to each criterion can be calculated as:

$\tilde{x}_{i j}=\frac{1}{K}\left[\tilde{x}_{i j}^{1}+\tilde{x}_{i j}^{2}+\cdots+\tilde{x}_{i j}^{K}\right]$

$w_{j}=\frac{1}{K}\left[\tilde{w}_{j}^{1}+\tilde{w}_{j}^{2}+\cdots+\tilde{w}_{j}^{K}\right]$

where $\tilde{x}_{i j}^{K}$ and $\tilde{w}_{j}^{K}$ are the rating and the importance weight of the Kth decision-maker. 
Step 2 A decision matrix is formed.

$\tilde{D}=\left[\begin{array}{cccc}\tilde{x}_{11} & \tilde{x}_{12} & \ldots & \tilde{x}_{1 n} \\ \tilde{x}_{21} & \tilde{x}_{22} & \ldots & \tilde{x}_{2 n} \\ \ldots & \ldots & \ldots & \ldots \\ \tilde{x}_{m 1} & \tilde{x}_{m 2} & \ldots & \tilde{x}_{m n}\end{array}\right]$

$\tilde{\widehat{W}}=\left[\tilde{w}_{1}, \tilde{w}_{2}, \ldots, \tilde{w}_{n}\right]$

where $\tilde{x}_{i j}, \forall i, j$ and $\tilde{w}_{j}, j=1,2, \ldots, n$ are linguistic variables. These linguistic variables can be described by trapezoidal fuzzy numbers, $\tilde{x}_{i j}=\left(a_{i j}, b_{i j}, c_{i j}, d_{i j}\right)$ and $\tilde{w}_{j}=\left(w_{j 1}, w_{j 2}, w_{j 3}, w_{j 4}\right)$.

Step 3 To avoid complexity of mathematical operations in a decision process, the linear scale transformation is used here to transform the various criteria scales into comparable scales. The set of criteria can be divided into benefit criteria $(B)$ and cost criteria $(C)$. Therefore, the normalized fuzzy decision matrix can be represented as:

$\tilde{R}_{i j}=\left[\tilde{r}_{i j}\right]_{m \times n}$

where $B$ and $C$ are the sets of benefit criteria and cost criteria, respectively, and,

$\tilde{r}_{i j}=\left(\frac{a_{i j}}{d_{j}^{*}}, \frac{b_{i j}}{d_{j}^{*}} \frac{c_{i j}}{d_{j}^{*}} \frac{d_{i j}}{d_{j}^{*}}\right), \quad j \in B$,

$\tilde{r}_{i j}=\left(\frac{a_{j}^{-}}{d_{i j}}, \frac{a_{j}^{-}}{c_{i j}} \frac{a_{j}^{-}}{b_{i j}} \frac{a_{j}^{-}}{a_{i j}}\right), \quad j \in C$,

$d_{j}^{*}=\max _{i} d_{i j}, \quad j \in B$,

$a_{j}^{-}=\min _{i} a_{i j}, \quad j \in C$.

Step 4 Considering the different weights of each criterion, the weighted normalized decision matrix is computed by multiplying the importance weight of evaluation criteria and the values in the normalized decision matrix. The weighted normalized decision matrix $\tilde{V}$ for each criterion is defined as:

$\tilde{V}=\left[\tilde{v}_{i j}\right]_{m \times n}$ for $i=1,2, \ldots, m$ and $j=1,2, \ldots, n$

where $\tilde{v}_{i j}=\tilde{r}_{i j} \times \tilde{w}_{j}$ here $\tilde{v}_{i j}$ denotes normalized positive trapezoidal fuzzy numbers.

Step 5 Then, fuzzy positive $\tilde{A}^{+}$and fuzzy negative $\tilde{A}^{-}$ ideal solutions are determined. The fuzzy positive ideal solutions (FPIS, $\tilde{A}^{+}$) and the fuzzy negative ideal solution (FNIS, $\tilde{A}^{-}$) can be defined for beneficial criteria.

$\tilde{A}^{*}=\left(\tilde{v}_{1}^{*}, \tilde{v}_{2}^{*}, \ldots, \tilde{v}_{n}^{*}\right)$

$\tilde{A}^{-}=\left(\tilde{v}_{1}^{-}, \tilde{v}_{2}^{-}, \ldots, \tilde{v}_{n}^{-}\right)$

where $\tilde{v}_{j}^{*}=(1,1,1,1)$ and $\tilde{v}_{j}^{-}=(0,0,0,0)$ for $j=1, \ldots, n$.
Step 6 The distance of each alternative from the positive ideal solution $d_{i}^{+}$and the negative ideal solution $d_{i}^{-}$is calculated.

$d_{i}^{+}=\sum_{j=1}^{n} \sqrt{\left(\tilde{v}_{i j}-\tilde{v}_{j}^{*}\right)^{2}} \quad i=1,2, \ldots, m$

$d_{i}^{-}=\sum_{j=1}^{n} \sqrt{\left(\tilde{v}_{i j}-\tilde{v}_{j}^{-}\right)^{2}} \quad i=1,2, \ldots, m$

where $d(\cdot, \cdot)$ is the distance measurement between two fuzzy numbers.

Step 7 Then, the fuzzy closeness coefficient $\mathrm{CC}_{i}$ is determined.

$\mathrm{CC}_{i}=d_{i}^{-} /\left(d_{i}^{-}+d_{i}^{+}\right)$

Step 8 Rank the preference order. Using this index, the alternatives can be ranked in decreasing order.

\section{Fuzzy GRA}

GRA is a MCDM method that was originally proposed by Deng $(1982,1989)$. It has been applied in solving a variety of MCDM problems by many authors. For example, Wang (2009) apply fuzzy GRA to evaluate financial performance of Taiwan container lines. Wei (2010) proposes a GRA with intuitionistic fuzzy information in which the information about attribute weights is incompletely known. Zhang and Liu (2011) propose a GRA-based intuitionistic fuzzy MCDM method and apply to personnel selection problem. The steps of the fuzzy GRA algorithm can be outlined as follows (Chen and Tzeng 2004; Wei 2010):

Step 1 In the first step, a panel of decision-makers (DMs) who are knowledgeable about 3PLs selection process is established.

$\tilde{x}_{i j}=\frac{1}{K}\left[\tilde{x}_{i j}^{1}+\cdots+\tilde{x}_{i j}^{K}\right]=\frac{1}{K} \sum_{e=1}^{K} \tilde{x}_{i j}^{e}$

Step 2 Calculate the normalized decision matrix.

Larger the better $\tilde{r}_{i j}=\frac{\tilde{x}_{i j}-\min \left(\tilde{x}_{i j}\right)}{\max \left(\tilde{x}_{i j}\right)-\min \left(\tilde{x}_{i j}\right)}$

Smaller the better $\tilde{r}_{i j}=\frac{\min \left(\tilde{x}_{i j}\right)-\tilde{x}_{i j}}{\max \left(\tilde{x}_{i j}\right)-\min \left(\tilde{x}_{i j}\right)}$

Nominal - the - best $\tilde{r}_{i j}=\frac{\left|\tilde{x}_{i j}-\tilde{x}_{\mathrm{o} j}\right|}{\max \left\{\max \left(\tilde{x}_{i j}\right)-\tilde{x}_{\mathrm{o} j}, x_{\mathrm{o} j}-\min \left(\tilde{x}_{i j}\right)\right\}}$

where $\tilde{x}_{\mathrm{o} j}$ is optimal value of $j$ th criterion.

Step 3 Determine the reference series. The reference series can be defined as: 
$\tilde{R}_{0}=\left[\tilde{r}_{01}, \tilde{r}_{02}, \ldots, \tilde{r}_{0 n},\right] \quad$ where $\quad \tilde{r}_{0 j}=\max \left(\tilde{r}_{i j}\right)$

$j=1, \ldots, n$

Step 4 Establish the distance matrix. The distance $\tilde{\delta}_{i j}$ between the reference value and each comparison value is given as:

$\tilde{\delta}_{i j}=\left|\tilde{r}_{0 j}-\tilde{r}_{i j}\right|$

Then, the distance matrix $\Delta$ can be obtained as:

$\Delta=\left[\begin{array}{cccc}\tilde{\delta}_{11} & \tilde{\delta}_{12} & \ldots & \tilde{\delta}_{1 n} \\ \tilde{\delta}_{21} & \tilde{\delta}_{22} & \ldots & \tilde{\delta}_{2 n} \\ \ldots & \ldots & \ldots & \ldots \\ \tilde{\tilde{\delta}}_{m 1} & \tilde{\tilde{\delta}}_{m 2} & \ldots & \tilde{\delta}_{m n}\end{array}\right]$

Step 5 Calculate the fuzzy grey relational coefficient. The fuzzy grey relational coefficient $\tilde{\xi}_{i j}$ is defined as: $\tilde{\xi}_{i j}=$ $\frac{\tilde{\delta}_{\min }+\zeta \tilde{\delta}_{\max }}{\tilde{\delta}_{i j}+\zeta \tilde{\delta}_{\max }} \tilde{\delta}_{\max }=\max \left(\tilde{\delta}_{i j}\right), \tilde{\delta}_{\min }=\min \left(\tilde{\delta}_{i j}\right)$ and $\zeta$ resolving coefficient $\zeta \in[0,1]$.

Step 6 Estimate the fuzzy grey relational grade $\tilde{\gamma}_{i}$ by the relation

$\tilde{\gamma}_{i}=\sum_{j=1}^{n} \tilde{w}_{j} \tilde{\xi}_{i j}, \quad i=1, \ldots, m$

where $\tilde{w}_{j}$ is the weight of the $j$ th criterion, and $\sum_{j=1}^{n} \tilde{w}_{j}=\tilde{1}$

\section{The proposed combined fuzzy TOPSIS and GRA method}

In this section, a fuzzy MCDM method is presented to evaluate greenness of 3PLs. The proposed method can be applied to a complex decision-making problem containing imprecise, indefinite and subjective data or vague information. The combined fuzzy TOPSIS and GRA method is proposed to solve fuzzy MCDM problems. A triangular or trapezoidal fuzzy number is usually adopted to express the decision-maker's evaluation on alternatives with respect to each criterion. Indeed, a triangular fuzzy number is a special version of a trapezoidal fuzzy number. When the two most promising values are equal, the trapezoidal fuzzy number becomes a triangular fuzzy number. Therefore, a trapezoidal fuzzy number can represent more general situations. Membership function $\mu_{\tilde{A}}(x)$ of a trapezoidal fuzzy number $\tilde{A}=\left(a_{1}, a_{2}, a_{3}, a_{4}\right)$ is defined as:

$\mu_{\tilde{A}}(x)= \begin{cases}\frac{0,}{x-a_{1}}, & x<a_{1} \\ \frac{a_{2}-a_{1}}{1,} & a_{1} \leq x \leq a_{2} \\ \frac{x-a_{1}}{a_{1}-a_{1}}, & a_{2} \leq x \leq a_{3} \\ 0, & x>a_{3} \leq a_{4}\end{cases}$
By the extension principle, the fuzzy sum and subtraction of any two trapezoidal fuzzy numbers are also trapezoidal fuzzy numbers. But the multiplication of any two trapezoidal fuzzy numbers is only an approximate trapezoidal fuzzy number. Given any two positive trapezoidal fuzzy numbers, $\tilde{A}=\left(a_{1}, a_{2}, a_{3}, a_{4}\right), \quad \tilde{B}=$ $\left(b_{1}, b_{2}, b_{3}, b_{4}\right)$ and $k$ is real number, some operations of fuzzy numbers $\tilde{A}$ and $\tilde{B}$ can be calculated as follows:

$\tilde{A}+\tilde{B}=\left(a_{1}+b_{1}, a_{2}+b_{2}, a_{3}+b_{3}, a_{4}+b_{4}\right)$

$\tilde{A}-\tilde{B}=\left(a_{1}-b_{1}, a_{2}-b_{2}, a_{3}-b_{3}, a_{4}-b_{4}\right)$

$\tilde{A} \times \tilde{B} \cong\left(a_{1} \times b_{1}, a_{2} \times b_{2}, a_{3} \times b_{3}, a_{4} \times b_{4}\right)$

$\tilde{A} \times k \cong\left(a_{1} \times k, a_{2} \times k, a_{3} \times k, a_{4} \times k\right)$

In the proposed method, the criteria weights are generated by a fuzzy AHP procedure. It is easy to extend to the fuzzy case and guarantees a unique solution to the reciprocal comparison matrix, and the steps of this approach are relatively easier than the other fuzzy AHP approaches. The ranking of 3PLs is calculated by the combined fuzzy TOPSIS and GRA method. The steps (1-3) used for the Buckley's fuzzy AHP algorithm (Buckley 1985; Gumus 2009; Chen 2009), and the steps (4-13) of the proposed combined fuzzy TOPSIS and GRA algorithm can be summarized as follows:

Step 1 Construct pairwise comparison matrices amongst all the criteria in the hierarchical structure. Assign linguistic terms as given in Table 1, to the pairwise comparisons by asking which is the more important of each two criteria.

Step 2 Use geometric mean technique to define the fuzzy geometric mean as follows:

$\tilde{r}_{j}=\left[\prod_{l=1}^{n} \tilde{r}_{j l}\right]^{1 / n} \quad$ for $\quad j, l=1,2, \ldots, n$

where $\tilde{r}_{j l}$ is fuzzy comparison value for criterion $j$ to criterion $l$; thus, it is geometric mean of fuzzy comparison value of criterion $j$ to each criterion.

Step 3 Calculate the fuzzy weights of each criterion using

$\tilde{w}_{j}=\tilde{r}_{j} \otimes\left[\sum_{j=1}^{n} \tilde{r}_{j}\right]^{-1}$

where $\tilde{w}_{j}$ is the fuzzy weight of the $j$ th criterion, can be indicated by $\tilde{w}_{j}=\left(w_{j 1}, w_{j 2}, w_{j 3}, w_{j 4}\right)$. Here $\left(w_{j 1}, w_{j 2}, w_{j 3}\right.$, $w_{j 4}$ ) stand for the lower, middle and upper values of the fuzzy weight of the $j$ th criterion, respectively.

Step 4 In this step, a panel of decision-makers (DMs) who are knowledgeable about 3PLs and evaluation process is established. 
Table 1 Linguistic scale for importance

\begin{tabular}{lll}
\hline Linguistic scale for importance & Trapezoidal fuzzy scale & Trapezoidal fuzzy reciprocal scale \\
\hline Equal (E) & $(1,1,1,1)$ & $(1,1,1,1)$ \\
Weakly important (WI) & $(1,3,3,5)$ & $(1 / 5,1 / 3,1 / 3,1)$ \\
Fairly important (FI) & $(3,5,6,7)$ & $(1 / 7,1 / 6,1 / 5,1 / 3)$ \\
Very strongly important (VSI) & $(5,7,8,9)$ & $(1 / 9,1 / 8,1 / 7,1 / 5)$ \\
Absolutely important (AI) & $(7,9,9,10)$ & $(1 / 10,1 / 9,1 / 9,1 / 7)$ \\
\hline
\end{tabular}

$\tilde{x}_{i j}=\frac{1}{K}\left[\tilde{x}_{i j}^{1}+\tilde{x}_{i j}^{2}+\cdots+\tilde{x}_{i j}^{K}\right]=\frac{1}{K} \sum_{e=1}^{K} \tilde{x}_{i j}^{e}$

where $\tilde{x}_{i j}^{t}$ is the fuzzy value assigned by $t$ th judgment.

Step 5 A decision matrix is formed.

$\tilde{A}=\left[\begin{array}{cccc}\tilde{x}_{11} & \tilde{x}_{12} & \ldots & \tilde{x}_{1 n} \\ \tilde{x}_{21} & \tilde{x}_{22} & \ldots & \tilde{x}_{2 n} \\ \ldots & \ldots & \ldots & \ldots \\ \tilde{x}_{m 1} & \tilde{x}_{m 2} & \ldots & \tilde{x}_{m n}\end{array}\right]=\left[\tilde{x}_{i j}\right]_{m \times n}$

Step 6 Normalization based on the characteristics of three types of criteria, namely larger-the-better (benefit), smaller-the-better (cost) or nominal-the-best (optimal), is used here to transform the various criteria scales into comparable scales.

Larger the better $\tilde{r}_{i j}=\frac{\tilde{x}_{i j}-\min \left(\tilde{x}_{i j}\right)}{\max \left(\tilde{x}_{i j}\right)-\min \left(\tilde{x}_{i j}\right)}$

Smaller the better $\tilde{r}_{i j}=\frac{\min \left(\tilde{x}_{i j}\right)-\tilde{x}_{i j}}{\max \left(\tilde{x}_{i j}\right)-\min \left(\tilde{x}_{i j}\right)}$

Nominal the best $\tilde{r}_{i j}=\frac{\left|\tilde{x}_{i j}-\tilde{x}_{\mathrm{o} j}\right|}{\max \left\{\max \left(\tilde{x}_{i j}\right)-\tilde{x}_{\mathrm{o} j}, x_{\mathrm{oj}}-\min \left(\tilde{x}_{i j}\right)\right\}}$

Step 7 Considering the different weights of each criterion, the weighted normalized decision matrix is computed by multiplying the importance weights of evaluation criteria and the values in the normalized decision matrix. The weighted normalized decision matrix $\tilde{V}$ for each criterion is defined as:

$\tilde{V}=\left[\tilde{v}_{i j}\right]_{m \times n}$ for $i=1,2, \ldots, m$ and $j=1,2, \ldots, n$

where $\tilde{v}_{i j}=\tilde{r}_{i j} \times \tilde{w}_{j}$ here $\tilde{v}_{i j}$ denotes normalized positive trapezoidal fuzzy numbers and $\tilde{v}_{i j}=\left(a_{i j}^{*}, b_{i j}^{*}, c_{i j}^{*}, d_{i j}^{*}\right), i=$ $1,2, \ldots, m ; j=1,2, \ldots, n . \quad \tilde{r}_{i j} \quad$ is obtained by using Eqs. (5)-(7).
Step 8 Then, fuzzy positive $\tilde{A}^{+}$and fuzzy negative $\tilde{A}^{-}$ ideal solutions are determined as the referential sequences. It can be defined for beneficial criteria as follows.

$\tilde{A}^{+}=\left(\max _{j} v_{i j}\right)=\left(\tilde{v}_{1}^{+}, \tilde{v}_{2}^{+}, \ldots, \tilde{v}_{m}^{+}\right), \quad i=1,2, \ldots, m$.

$\tilde{A}^{-}=\left(\min _{j} v_{i j}\right)=\left(\tilde{v}_{1}^{-}, \tilde{v}_{2}^{-}, \ldots \tilde{v}_{m}^{-}\right), \quad i=1,2, \ldots, m$.

where $v_{i}^{+}=\left(a_{i}^{+}, b_{i}^{+}, c_{i}^{+}, d_{i}^{+}\right)$and $v_{i}^{-}=\left(a_{i}^{-}, b_{i}^{-}, c_{i}^{-}, d_{i}^{-}\right)$, $i=1,2, \ldots, m$.

Step 9 The different separation measures of each alternative are calculated in order to determine the grey relational coefficient of each alternative from PIS and NIS. The separation between alternatives can be measured by Hamming distance $(d)$, normalized Hamming distance $(l)$, Euclidean distance $(q)$ and normalized Euclidean distance (h). Several definitions are considered that proposed by Park et al. (2008) and consist of Hamming, Euclidean and their normalized version, which are proposed by Burillo and Bustince (1996) and Grzegorzewski (2004), respectively. Park et al. (2011a; 2011b) applied these separation measures to TOPSIS and VIKOR under interval-valued intuitionistic fuzzy information, respectively. These separation measures are applied for trapezoidal fuzzy numbers in the proposed combined fuzzy TOPSIS-GRA method.

Separation measures based on the Hamming distance (d)

1. The extension of Burillo and Bustince's method,

$A_{j^{*}}^{d_{1}}=\frac{1}{4} \sum_{i=1}^{n}\left[\left|a_{i j}^{*}-a_{i}^{+}\right|+\left|b_{i j}^{*}-b_{i}^{+}\right|+\left|c_{i j}^{*}-c_{i}^{+}\right|+\left|d_{i j}^{*}-d_{i}^{+}\right|\right]$

$A_{j^{-}}^{d_{1}}=\frac{1}{4} \sum_{i=1}^{n}\left[\left|a_{i j}^{*}-a_{i}^{-}\right|+\left|b_{i j}^{*}-b_{i}^{-}\right|+\left|c_{i j}^{*}-c_{i}^{-}\right|+\left|d_{i j}^{*}-d_{i}^{-}\right|\right]$ 
2. The extension of modified Burillo and Bustince's 3. The extension of Grzegorzewski's method, method,

$$
\begin{aligned}
& A_{j^{*}}^{d_{2}}=\frac{1}{4} \sum_{i=1}^{n}\left[\left|a_{i j}^{*}-a_{i}^{+}\right|+\left|b_{i j}^{*}-b_{i}^{+}\right|+\left|c_{i j}^{*}-c_{i}^{+}\right|+\left|d_{i j}^{*}-d_{i}^{+}\right|+|| a_{i j}^{*}-b_{i j}^{*}|-| a_{i}^{+}-b_{i}^{+}||+|| c_{i j}^{*}-d_{i j}^{*}|+| c_{i}^{+}-d_{i}^{+}||\right] \\
& A_{j^{\prime}}^{d_{2}}=\frac{1}{4} \sum_{i=1}^{n}\left[\left|a_{i j}^{*}-a_{i}^{-}\right|+\left|b_{i j}^{*}-b_{i}^{-}\right|+\left|c_{i j}^{*}-c_{i}^{-}\right|+\left|d_{i j}^{*}-d_{i}^{-}\right|+|| a_{i j}^{*}-b_{i j}^{*}|-| a_{i}^{-}-b_{i}^{-}||+|| c_{i j}^{*}-d_{i j}^{*}|+| c_{i}^{-}-d_{i}^{-}||\right]
\end{aligned}
$$

3. The extension of Grzegorzewski's method,

$$
\begin{aligned}
A_{j^{*}}^{d_{H}}= & \frac{1}{2} \sum_{i=1}^{n}\left[\max \left(\left|a_{i j}^{*}-a_{i}^{+}\right|,\left|b_{i j}^{*}-b_{i}^{+}\right|\right)\right. \\
& \left.+\max \left(\left|c_{i j}^{*}-c_{i}^{+}\right|,\left|d_{i j}^{*}-d_{i}^{+}\right|\right)\right] \\
A_{j^{-}}^{d_{H}}= & \frac{1}{2} \sum_{i=1}^{n}\left[\max \left(\left|a_{i j}^{*}-a_{i}^{-}\right|,\left|b_{i j}^{*}-b_{i}^{-}\right|\right)\right. \\
& \left.+\max \left(\left|c_{i j}^{*}-c_{i}^{-}\right|,\left|d_{i j}^{*}-d_{i}^{-}\right|\right)\right]
\end{aligned}
$$

Separation measures based on the normalized Hamming distance (l)

1. The extension of Burillo and Bustince's method,

$$
\begin{aligned}
& A_{j^{*}}^{l_{1}}=\frac{1}{4 m} \sum_{i=1}^{n}\left[\left|a_{i j}^{*}-a_{i}^{+}\right|+\left|b_{i j}^{*}-b_{i}^{+}\right|+\left|c_{i j}^{*}-c_{i}^{+}\right|+\left|d_{i j}^{*}-d_{i}^{+}\right|\right] \\
& A_{j^{-}}^{l_{1}}=\frac{1}{4 m} \sum_{i=1}^{n}\left[\left|a_{i j}^{*}-a_{i}^{-}\right|+\left|b_{i j}^{*}-b_{i}^{-}\right|+\left|c_{i j}^{*}-c_{i}^{-}\right|+\left|d_{i j}^{*}-d_{i}^{-}\right|\right]
\end{aligned}
$$

2. The extension of modified Burillo and Bustince's method,

$$
\begin{aligned}
A_{j^{*}}^{l_{H}}= & \frac{1}{2 m} \sum_{i=1}^{n}\left[\max \left(\left|a_{i j}^{*}-a_{i}^{+}\right|,\left|b_{i j}^{*}-b_{i}^{+}\right|\right)\right. \\
& \left.+\max \left(\left|c_{i j}^{*}-c_{i}^{+}\right|,\left|d_{i j}^{*}-d_{i}^{+}\right|\right)\right] \\
A_{j^{-}}^{l_{H}}= & \frac{1}{2 m} \sum_{i=1}^{n}\left[\max \left(\left|a_{i j}^{*}-a_{i}^{-}\right|,\left|b_{i j}^{*}-b_{i}^{-}\right|\right)\right. \\
& \left.+\max \left(\left|c_{i j}^{*}-c_{i}^{-}\right|,\left|d_{i j}^{*}-d_{i}^{-}\right|\right)\right]
\end{aligned}
$$

Separation measures based on the Euclidean distance $(q)$

1. The extension of Burillo and Bustince's method,

$$
\begin{aligned}
A_{j^{*}}^{e_{1}}= & \left\{\frac { 1 } { 4 } \sum _ { i = 1 } ^ { n } \left[\left(a_{i j}^{*}-a_{i}^{+}\right)^{2}+\left(b_{i j}^{*}-b_{i}^{+}\right)^{2}\right.\right. \\
& \left.\left.+\left(c_{i j}^{*}-c_{i}^{+}\right)^{2}+\left(d_{i j}^{*}-d_{i}^{+}\right)^{2}\right]\right\}^{\frac{1}{2}} \\
A_{j^{-}}^{e_{1}}= & \left\{\frac { 1 } { 4 } \sum _ { i = 1 } ^ { n } \left[\left(a_{i j}^{*}-a_{i}^{-}\right)^{2}+\left(b_{i j}^{*}-b_{i}^{-}\right)^{2}\right.\right. \\
& \left.\left.+\left(c_{i j}^{*}-c_{i}^{-}\right)^{2}+\left(d_{i j}^{*}-d_{i}^{-}\right)^{2}\right]\right\}^{\frac{1}{2}}
\end{aligned}
$$

$$
\begin{aligned}
& A_{j^{*}}^{l_{2}}=\frac{1}{4 m} \sum_{i=1}^{n}\left[\left|a_{i j}^{*}-a_{i}^{+}\right|+\left|b_{i j}^{*}-b_{i}^{+}\right|+\left|c_{i j}^{*}-c_{i}^{+}\right|+\left|d_{i j}^{*}-d_{i}^{+}\right|+|| a_{i j}^{*}-b_{i j}^{*}|-| a_{i}^{+}-b_{i}^{+}||+|| c_{i j}^{*}-d_{i j}^{*}|+| c_{i}^{+}-d_{i}^{+}||\right] \\
& A_{j^{=}}^{l_{2}}=\frac{1}{4 m} \sum_{i=1}^{n}\left[\left|a_{i j}^{*}-a_{i}^{-}\right|+\left|b_{i j}^{*}-b_{i}^{-}\right|+\left|c_{i j}^{*}-c_{i}^{-}\right|+\left|d_{i j}^{*}-d_{i}^{-}\right|+|| a_{i j}^{*}-b_{i j}^{*}|-| a_{i}^{-}-b_{i}^{-}||+|| c_{i j}^{*}-d_{i j}^{*}|+| c_{i}^{-}-d_{i}^{-}||\right]
\end{aligned}
$$


2. The extension of modified Burillo and Bustince's method
2. The extension of modified Burillo and Bustince's method,

$$
\begin{aligned}
& A_{j^{*}}^{e_{2}}=\left\{\frac{1}{4} \sum_{i=1}^{n}\left[\left(a_{i j}^{*}-a_{i}^{+}\right)^{2}+\left(b_{i j}^{*}-b_{i}^{+}\right)^{2}+\left(c_{i j}^{*}-c_{i}^{+}\right)^{2}+\left(d_{i j}^{*}-d_{i}^{+}\right)^{2}+\left(\left|a_{i j}^{*}-b_{i j}^{*}\right|-\left|a_{i}^{+}-b_{i}^{+}\right|\right)^{2}+\left(\left|c_{i j}^{*}-d_{i j}^{*}\right|+\left|c_{i}^{+}-d_{i}^{+}\right|\right)^{2}\right]\right\}^{\frac{1}{2}} \\
& A_{j^{=}}^{e_{2}}=\left\{\frac{1}{4} \sum_{i=1}^{n}\left[\left(a_{i j}^{*}-a_{i}^{-}\right)^{2}+\left(b_{i j}^{*}-b_{i}^{-}\right)^{2}+\left(c_{i j}^{*}-c_{i}^{-}\right)^{2}+\left(d_{i j}^{*}-d_{i}^{-}\right)^{2}+\left(\left|a_{i j}^{*}-b_{i j}^{*}\right|-\left|a_{i}^{-}-b_{i}^{-}\right|\right)^{2}+\left(\left|c_{i j}^{*}-d_{i j}^{*}\right|+\left|c_{i}^{-}-d_{i}^{-}\right|\right)^{2}\right]\right\}^{\frac{1}{2}}
\end{aligned}
$$

$$
\begin{aligned}
& A_{j^{*}}^{q_{2}}=\left\{\frac{1}{4 m} \sum_{i=1}^{n}\left[\left(a_{i j}^{*}-a_{i}^{+}\right)^{2}+\left(b_{i j}^{*}-b_{i}^{+}\right)^{2}+\left(c_{i j}^{*}-c_{i}^{+}\right)^{2}+\left(d_{i j}^{*}-d_{i}^{+}\right)^{2}+\left(\left|a_{i j}^{*}-b_{i j}^{*}\right|-\left|a_{i}^{+}-b_{i}^{+}\right|\right)^{2}+\left(\left|c_{i j}^{*}-d_{i j}^{*}\right|+\left|c_{i}^{+}-d_{i}^{+}\right|\right)^{2}\right]\right\}^{\frac{1}{2}} \\
& A_{j^{*}}^{q_{2}}=\left\{\frac{1}{4 m} \sum_{i=1}^{n}\left[\left(a_{i j}^{*}-a_{i}^{-}\right)^{2}+\left(b_{i j}^{*}-b_{i}^{-}\right)^{2}+\left(c_{i j}^{*}-c_{i}^{-}\right)^{2}+\left(d_{i j}^{*}-d_{i}^{-}\right)^{2}+\left(\left|a_{i j}^{*}-b_{i j}^{*}\right|-\left|a_{i}^{-}-b_{i}^{-}\right|\right)^{2}+\left(\left|c_{i j}^{*}-d_{i j}^{*}\right|+\left|c_{i}^{-}-d_{i}^{-}\right|\right)^{2}\right]\right\}^{\frac{1}{2}}
\end{aligned}
$$

3. The extension of Grzegorzewski's method

$$
\begin{aligned}
A_{j^{*}}^{e_{\mathrm{H}}}= & \left\{\frac { 1 } { 2 } \sum _ { i = 1 } ^ { n } \left[\left(\max \left(\left|a_{i j}^{*}-a_{i}^{+}\right|,\left|b_{i j}^{*}-b_{i}^{+}\right|\right)\right)^{2}\right.\right. \\
& \left.\left.+\left(\max \left(\left|c_{i j}^{*}-c_{i}^{+}\right|,\left|d_{i j}^{*}-d_{i}^{+}\right|\right)\right)^{2}\right]\right\}^{\frac{1}{2}} \\
A_{j^{-}}^{e_{\mathrm{H}}}= & \left\{\frac { 1 } { 2 } \sum _ { i = 1 } ^ { n } \left[\left(\max \left(\left|a_{i j}^{*}-a_{i}^{-}\right|,\left|b_{i j}^{*}-b_{i}^{-}\right|\right)\right)^{2}\right.\right. \\
& \left.\left.+\left(\max \left(\left|c_{i j}^{*}-c_{i}^{-}\right|,\left|d_{i j}^{*}-d_{i}^{-}\right|\right)\right)^{2}\right]\right\}^{\frac{1}{2}}
\end{aligned}
$$

Separation measures based on the normalized Euclidean distance ( $h$ )

1. The extension of Burillo and Bustince's method,

$$
\begin{aligned}
A_{j^{*}}^{q_{1}}= & \left\{\frac { 1 } { 4 m } \sum _ { i = 1 } ^ { n } \left[\left(a_{i j}^{*}-a_{i}^{+}\right)^{2}+\left(b_{i j}^{*}-b_{i}^{+}\right)^{2}\right.\right. \\
& \left.\left.+\left(c_{i j}^{*}-c_{i}^{+}\right)^{2}+\left(d_{i j}^{*}-d_{i}^{+}\right)^{2}\right]\right\}^{\frac{1}{2}} \\
A_{j^{-}}^{q_{1}}= & \left\{\frac { 1 } { 4 m } \sum _ { i = 1 } ^ { n } \left[\left(a_{i j}^{*}-a_{i}^{-}\right)^{2}+\left(b_{i j}^{*}-b_{i}^{-}\right)^{2}\right.\right. \\
& \left.\left.+\left(c_{i j}^{*}-c_{i}^{-}\right)^{2}+\left(d_{i j}^{*}-d_{i}^{-}\right)^{2}\right]\right\}^{\frac{1}{2}}
\end{aligned}
$$

3. The extension of Grzegorzewski's method,

$$
\begin{aligned}
A_{j^{*}}^{q_{\mathrm{H}}} & =\left\{\frac { 1 } { 2 m } \sum _ { i = 1 } ^ { n } \left[\left(\max \left(\left|a_{i j}^{*}-a_{i}^{+}\right|,\left|b_{i j}^{*}-b_{i}^{+}\right|\right)\right)^{2}\right.\right. \\
& \left.\left.+\left(\max \left(\left|c_{i j}^{*}-c_{i}^{+}\right|,\left|d_{i j}^{*}-d_{i}^{+}\right|\right)\right)^{2}\right]\right\}^{\frac{1}{2}} \\
A_{j^{-}}^{q_{\mathrm{H}}} & =\left\{\frac { 1 } { 2 m } \sum _ { i = 1 } ^ { n } \left[\left(\max \left(\left|a_{i j}^{*}-a_{i}^{-}\right|,\left|b_{i j}^{*}-b_{i}^{-}\right|\right)\right)^{2}\right.\right. \\
& \left.\left.+\left(\max \left(\left|c_{i j}^{*}-c_{i}^{-}\right|,\left|d_{i j}^{*}-d_{i}^{-}\right|\right)\right)^{2}\right]\right\}^{\frac{1}{2}}
\end{aligned}
$$

Step 10 Calculate the grey relational coefficient of each alternative from PIS and NIS using the following equation, respectively.

$$
\begin{aligned}
\gamma^{+}\left(A_{j^{*}}\right) & =\frac{\min _{i} \min _{j} A_{j^{*}}+\zeta \max _{i} \max _{j} A_{j^{*}}}{A_{j^{*}}+\zeta \max _{i} \max _{j} A_{j^{*}}} \\
\gamma^{-}\left(A_{j^{-}}\right) & =\frac{\min _{i} \min _{j} A_{j^{-}}+\zeta \max _{i} \max _{j} A_{j^{-}}}{A_{j^{-}}+\zeta \max _{i} \max _{j} A_{j^{-}}}
\end{aligned}
$$

Step 11 The grey relational grade of each alternative from PIS and NIS is determined as follows.

$d_{i}^{+}=\sum_{j=1}^{n} \gamma^{+}\left(A_{j^{*}}\right)$ 
$d_{i}^{-}=\sum_{j=1}^{n} \gamma^{-}\left(A_{j^{-}}\right)$

Step 12 Then, the closeness coefficient $\mathrm{CC}_{i}$ is determined.

$\mathrm{CC}_{i}=d_{i}^{+} / d_{i}^{-}$

Step 13 Rank the preference order. Using this index, the alternatives can be ranked in decreasing order.

\section{Results and discussion}

\section{A case study}

In this section, first, a case study is structured considering five 3PL companies under several decision criteria which make 3PLs more "green". Then, the criteria weights and final ranking of alternatives are determined based on the proposed combined fuzzy TOPSIS-GRA method. Finally, the verification of the proposed methodology is conducted.

\section{The hierarchical structure}

Here, an empirical case is considered for evaluating green 3PLs serve in Istanbul, to illustrate the proposed method's applicability. The aim of the case is to show the advantages of the proposed method and select the greenest 3PL with respect to green criteria. The decision criteria and alternatives hierarchy are shown in Fig. 1.

In this part of our study, the most important criteria are determined for selecting and evaluating green 3PLs. The evaluation criteria are determined based on expert opinions, working in the logistics sector as manager and related studies such as Murphy et al. (1994), Noci (1997), Walton et al. (1998), Handfield et al. (2002), Humphreys et al. (2003), Yang and Wu (2007), Lee et al. (2009), Tuzkaya et al. (2009), Viswanathan, (2009), Kuo et al. (2010), Amindoust et al. (2012) and Buyukozkan (2012). Three decision-makers are consulted to obtain the weights of the criteria and the importance of green 3PLs with respect to criteria. Our experts are working as manager in the logistics sector. They work in the different companies within the same job position. Because the companies which worked by experts in are pioneers in their field and decision-makers that served as the manager, it is almost impossible to find any senior managers to score them. So, the weights of experts are considered as equal.

Five Turkish 3PLs that serve in Turkey are selected. These companies are listed alphabetically as Borusan Logistics, Ekol Logistics, Horoz Logistics, Omsan Logistics and Reysas Logistics. Only the names of 3PLs are mentioned because of privacy. In the final ranking, $A_{1}, A_{2}$, $A_{3}, A_{4}$ and $A_{5}$ are used for each 3PLs without giving their names. The criteria explanations are as below:

Cooperation with customer company and its customers $\left(\mathrm{C}_{1}\right)$ : That means not only 3PLs should take cognizance of greening issues, also customers and their customers should pay attention to protect environment (Walton et al. 1998).

Green government regulations $\left(\mathrm{C}_{2}\right)$ : Government agencies at state and local levels should work to build sustainable communities. Technologies and policies that are greening business need to be constituted. (Handfield et al. 2002; Kuo et al. 2010).

Environmental management system $\left(\mathrm{C}_{3}\right)$ : These activities may include environmentally relevant certificates (such

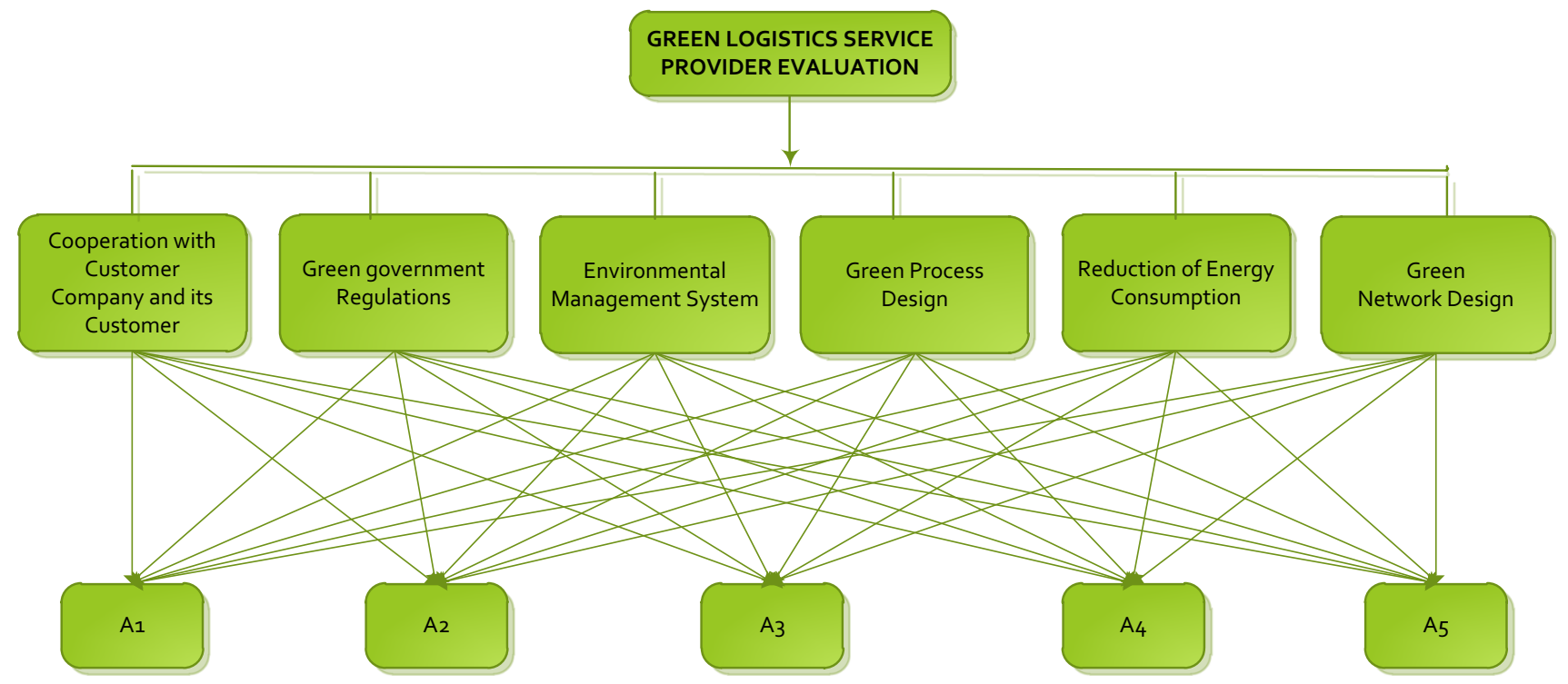

Fig. 1 The decision criteria and alternatives 
as ISO 14000, WEEE) and reverse logistics management programs. This should be containing to check supplier's environmental policies, implementation and certification (Buyukozkan 2012; Walton et al. 1998; Noci 1997; Murphy et al. 1994; Tuzkaya et al. 2009; Yang and Wu 2007; Humphreys et al. 2003; Amindoust et al. 2012).

Green process design $\left(\mathrm{C}_{4}\right)$ : Arise in pollution reveals inefficient use of inputs and eco-unfriendliness in one or more logistics activities, spanning from product design, production and distribution to disposal. Such problems can be prevented through redesigning the product and production processes (Noci 1997; Handfield et al. 2002; Lee et al. 2009; Humphreys et al. 2003; Amindoust et al. 2012).

Reduction in energy consumption $\left(\mathrm{C}_{5}\right)$ : With green logistics practices, 3PLs can reduce the amount of diesel consumptions by procuring state-of-the-art engines for trucks, using the scarce resources efficiently, converting roadway to railway if possible and using advanced fuel management system (Walton et al. 1998; Lee et al. 2009; Tuzkaya et al. 2009; Amindoust et al. 2012).

Green network design $\left(\mathrm{C}_{6}\right)$ : Green network enables companies to achieve the purpose of green supply chain movement by optimizing resources and reducing waste (Viswanathan 2009).

\section{Determination of criteria weights}

The importance values of criteria are determined via fuzzy AHP. The pairwise comparison scores are carried out by three experts using Table 2. In order to obtain the importance of each criterion, the experts applied a nine-point scale given in Table 1.

Consistency ratio (CR) for the defuzzified version is calculated as 0.080 , and it is $<0.10$. The results show that the decision matrix for the proposed hierarchical structure is consistent. The fuzzy weights of the criteria are given in Table 2. These weight values are used as inputs of the proposed method.

\section{The final ranking}

The importance of 3PLs with respect to criteria, assessed by decision-makers working in the logistic sector as manager, is presented in Table 3 as linguistic evaluations. Then, it is converted into trapezoidal fuzzy numbers to determine the average fuzzy performance values by using Eq. (3), with the guidance of experts, as given in Table 4.

Then, the normalized fuzzy decision matrix is calculated by using Eqs. (5)-(7). The weighted fuzzy normalized decision matrix is calculated by using Eq. (8) with respect to fuzzy weights of the criteria which are obtained by fuzzy AHP (Eqs. 1-2); it can be seen from Table 4. Also, the fuzzy positive and fuzzy negative ideal solutions are determined by using Eqs. (9)-(10), and they are given in Table 4.

Then, the grey relational coefficients of each alternative from PIS and NIS are calculated by using Eq. (11). In this step, as an example, the extension of Burillo and Bustince's method based on separation measures based on the Hamming distance $(d)$ is calculated in Table 5 .

In this study, as an extension, different separation measures are proposed for calculating the grey relational coefficient using Eqs. (11)-(22). The grey relational coefficient of each alternative from PIS and NIS is calculated using Eqs. (23)-(24). Here, the grey relational grade is calculated (Eqs. 25-26). Finally, the closeness coefficient

Table 3 Importance of green 3PLs with respect to criteria

\begin{tabular}{|c|c|c|c|c|c|c|c|}
\hline & & $\mathrm{C}_{1}$ & $\mathrm{C}_{2}$ & $\mathrm{C}_{3}$ & $\mathrm{C}_{4}$ & $\mathrm{C}_{5}$ & $\mathrm{C}_{6}$ \\
\hline \multirow[t]{5}{*}{$\mathrm{D}_{1}$} & $A_{1}$ & A & $\mathrm{FG}$ & VG & $\mathrm{G}$ & G & NB \\
\hline & $A_{2}$ & $\mathrm{P}$ & A & $\mathrm{P}$ & $\mathrm{G}$ & $\mathrm{P}$ & G \\
\hline & $A_{3}$ & $\mathrm{P}$ & $\mathrm{P}$ & A & FG & FG & $\mathrm{G}$ \\
\hline & $A_{4}$ & VG & VG & $\mathrm{FG}$ & $\mathrm{G}$ & G & NB \\
\hline & $A_{5}$ & $\mathrm{G}$ & $\mathrm{FG}$ & $\mathrm{G}$ & $\mathrm{G}$ & G & NB \\
\hline \multirow[t]{5}{*}{$\mathrm{D}_{2}$} & $A_{1}$ & VG & $\mathrm{PF}$ & $\mathrm{PF}$ & $\mathrm{G}$ & G & FG \\
\hline & $A_{2}$ & VG & A & A & A & VG & FG \\
\hline & $A_{3}$ & VG & $\mathrm{FG}$ & VG & VG & FG & FG \\
\hline & $A_{4}$ & $\mathrm{G}$ & $\mathrm{FG}$ & $\mathrm{FG}$ & FG & $\mathrm{PF}$ & FG \\
\hline & $A_{5}$ & $\mathrm{G}$ & $\mathrm{FG}$ & $\mathrm{FG}$ & FG & $\mathrm{PF}$ & FG \\
\hline \multirow[t]{5}{*}{$D_{3}$} & $A_{1}$ & VG & G & FG & $\mathrm{G}$ & $\mathrm{G}$ & PF \\
\hline & $A_{2}$ & A & A & A & VG & VG & FG \\
\hline & $A_{3}$ & A & VG & A & FG & FG & G \\
\hline & $A_{4}$ & G & $\mathrm{FG}$ & G & G & $\mathrm{PF}$ & PF \\
\hline & $A_{5}$ & $\mathrm{G}$ & $\mathrm{G}$ & $\mathrm{G}$ & $\mathrm{PF}$ & $\mathrm{PF}$ & NB \\
\hline
\end{tabular}

Table 2 Pairwise comparisons of evaluation criteria linguistically and trapezoidal fuzzy values

\begin{tabular}{llllllll}
\hline Criteria & $\mathrm{C}_{1}$ & $\mathrm{C}_{2}$ & $\mathrm{C}_{3}$ & $\mathrm{C}_{4}$ & $\mathrm{C}_{5}$ & $\mathrm{C}_{6}$ & Fuzzy weights \\
\hline $\mathrm{C}_{1}$ & $\mathrm{E}$ & $\mathrm{WI}$ & $\mathrm{FI}$ & $\mathrm{FI}$ & $\mathrm{FI}$ & FI & $(0.17 ; 0.43 ; 0.43 ; 0.98)$ \\
$\mathrm{C}_{2}$ & WLI & $\mathrm{E}$ & WI & FI & WI & FI & $(0.09 ; 0.25 ; 0.25 ; 0.67)$ \\
$\mathrm{C}_{3}$ & FLI & FLI & $\mathrm{E}$ & WI & WLI & E & $(0.03 ; 0.08 ; 0.08 ; 0.22)$ \\
$\mathrm{C}_{4}$ & FLI & FLI & WLI & E & FLI & WLI & $(0.02 ; 0.03 ; 0.03 ; 0.12)$ \\
$\mathrm{C}_{5}$ & FLI & WLI & WI & FI & E & WI & $(0.05 ; 0.14 ; 0.14 ; 0.4)$ \\
$\mathrm{C}_{6}$ & FLI & FLI & E & WI & WLI & E & $(0.03 ; 0.07 ; 0.07 ; 0.19)$ \\
\hline
\end{tabular}




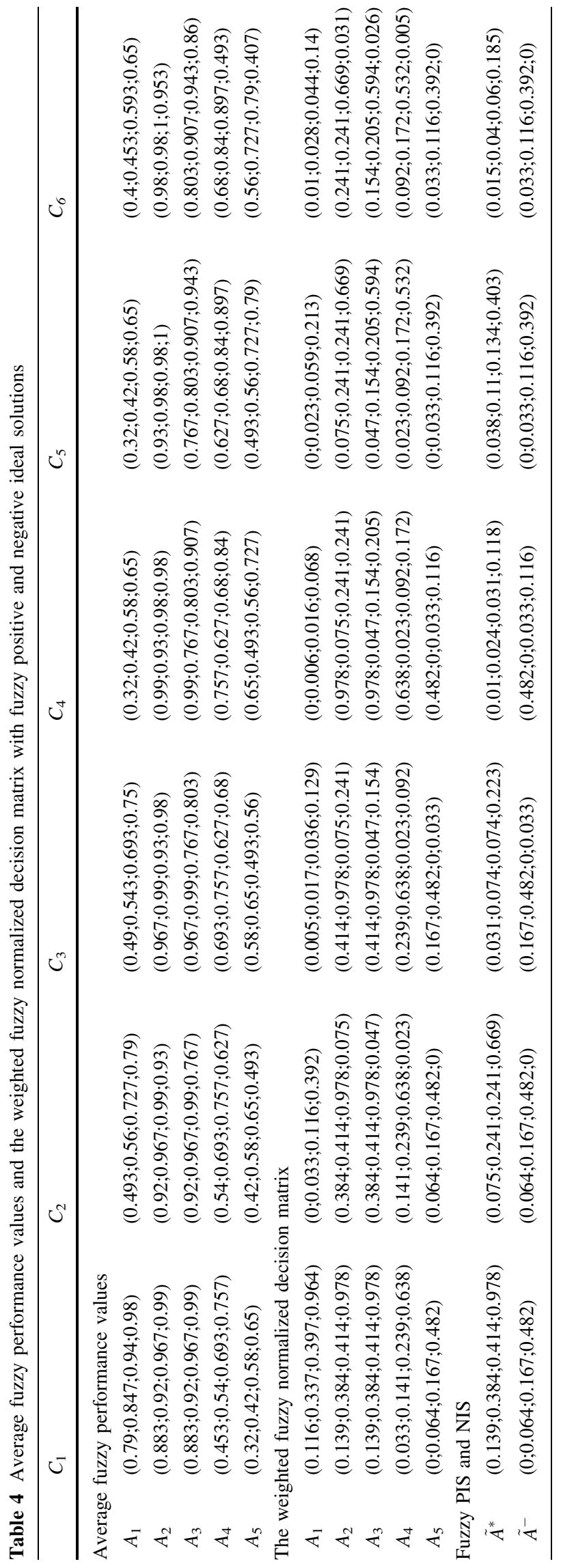

(Eq. 27) of each alternative is shown in the first column of Table 6. The resolving coefficient is assumed as $\zeta=0.5$.

The $\mathrm{CC}_{i}$ values of each 3PLs $A_{1}, A_{2}, A_{3}, A_{4}$ and $A_{5}$ are $0.6078,2.9659,1.9397,0.6481$ and 0.4073 , respectively. Therefore, the ranking order of the five 3PLs is $A_{2}>A_{3}>A_{4}>A_{1}>A_{5}$. Thus, it is clear that the most appropriate candidate is $A_{2}$. In this paper, the all separation measures are also used to calculate $\mathrm{CC}_{i}$ values of green 3PLs, and it is presented in Table 6. For example, the second column shows result of $\mathrm{CCi}$ values with respect to the extension of Burillo and Bustince's method (Eq. 11), and the third column shows the result of $\mathrm{CC}_{i}$ values with respect to the extension of modified Burillo and Bustince's method (Eq. 12).

\section{Verification and discussion}

The resolving coefficient value is used for sensitivity analysis in order to verify the proposed method, if it is rational and stable, or not. During verification process, it is observed that various resolving coefficient values, as the extension of Burillo and Bustince's method based on Hamming distance, do not affect the ranking order of the 3PLs (Fig. 2). Also, it can be said that the application of other separation measures does not affect the ranking order. But as the $\zeta$ value grows, the $\mathrm{CC}_{i}$ values of alternatives converge.

Table 7 shows the $\mathrm{CC}_{i}$ values based on different separation measures with respect to different $\zeta$ values. As seen from the table, $A_{2}$ is the greenest $3 \mathrm{PL}$ with respect to closeness coefficient $\mathrm{CC}_{i}$. The ranking order of the 3PLs does not change with the separation measure and $\zeta$ value changes. From the results of $\mathrm{CC}_{i}$, finally, the order of priority for 3PLs is obtained as $A_{2}>A_{3}>A_{4}>A_{1}>A_{5}$, with respect to different separation measures.

A comparative study is implemented with other methods to validate the efficiency and applicability of the proposed methods. The proposed method result, based on different separation measures, is compared with fuzzy TOPSIS and fuzz VIKOR results in order to verify the effectiveness of it, as seen in Table 8. The first comparative analysis is conducted with the results obtained by Chen (2000) for hiring a system analysis engineer for a software company as a personnel selection problem. The basic concept of the TOPSIS method is that the chosen alternative should display the shortest distance from the positive ideal solution and the farthest distance from the negative ideal solution. The ranking result of the alternatives yielded by the fuzzy TOPSIS method using a closeness coefficient approach (Chen 2000) is same to that obtained by the proposed method. The second comparative analysis is conducted with the results obtained by Kaya and Kahraman (2010) for selection of the best 
Table 5 Grey relational coefficient and grade of each alternative from PIS and NIS based on Hamming distance

\begin{tabular}{|c|c|c|c|c|c|c|c|c|c|c|c|c|c|c|}
\hline & \multicolumn{6}{|l|}{ PIS } & \multicolumn{6}{|l|}{ NIS } & \multirow[t]{2}{*}{$d^{+}$} & \multirow[t]{2}{*}{$d^{-}$} \\
\hline & $\mathrm{C}_{1}$ & $\mathrm{C}_{2}$ & $\mathrm{C}_{3}$ & $\mathrm{C}_{4}$ & $\mathrm{C}_{5}$ & $\mathrm{C}_{6}$ & $\mathrm{C}_{1}$ & $\mathrm{C}_{2}$ & $\mathrm{C}_{3}$ & $\mathrm{C}_{4}$ & $\mathrm{C}_{5}$ & $\mathrm{C}_{6}$ & & \\
\hline$A_{1}$ & 0.86 & 0.33 & 0.36 & 0.36 & 0.33 & 0.56 & 0.35 & 1 & 0.81 & 1 & 1 & 0.45 & 2.805 & 4.614 \\
\hline$A_{2}$ & 1 & 1 & 1 & 0.97 & 1 & 1 & 0.33 & 0.33 & 0.33 & 0.34 & 0.34 & 0.33 & 5.965 & 2.011 \\
\hline$A_{3}$ & 1 & 0.6 & 0.85 & 1 & 0.47 & 0.7 & 0.33 & 0.43 & 0.36 & 0.33 & 0.54 & 0.39 & 4.615 & 2.379 \\
\hline$A_{4}$ & 0.41 & 0.46 & 0.39 & 0.44 & 0.33 & 0.56 & 0.64 & 0.55 & 0.71 & 0.64 & 1 & 0.45 & 2.587 & 3.992 \\
\hline$A_{5}$ & 0.33 & 0.33 & 0.33 & 0.56 & 0.33 & 0.33 & 1 & 1 & 1 & 0.47 & 1 & 1 & 2.228 & 5.471 \\
\hline
\end{tabular}

Table $6 \mathrm{CC}_{\mathrm{i}}$ values for each separation measure

\begin{tabular}{lllllllllllll}
\hline & $d_{1}$ & $d_{2}$ & $d_{\mathrm{h}}$ & $l_{1}$ & $l_{2}$ & $l_{\mathrm{h}}$ & $e_{1}$ & $e_{2}$ & $e_{\mathrm{h}}$ & $q_{1}$ & $q_{2}$ & $q_{\mathrm{h}}$ \\
\hline$A_{1}$ & 0.61 & 0.61 & 0.61 & 0.61 & 0.61 & 0.61 & 0.61 & 1.14 & 0.61 & 0.61 & 1.14 & 0.61 \\
$A_{2}$ & 2.97 & 2.98 & 2.95 & 2.97 & 2.98 & 2.95 & 2.94 & 1.37 & 2.97 & 2.94 & 1.37 & 2.97 \\
$A_{3}$ & 1.94 & 1.93 & 1.96 & 1.94 & 1.93 & 1.96 & 1.97 & 1.32 & 1.96 & 1.97 & 1.32 & 1.96 \\
$A_{4}$ & 0.65 & 0.65 & 0.65 & 0.65 & 0.65 & 0.65 & 0.66 & 1.03 & 0.66 & 0.66 & 1.03 & 0.66 \\
$A_{5}$ & 0.41 & 0.41 & 0.41 & 0.41 & 0.41 & 0.41 & 0.41 & 0.90 & 0.41 & 0.41 & 0.90 & 0.41 \\
\hline
\end{tabular}

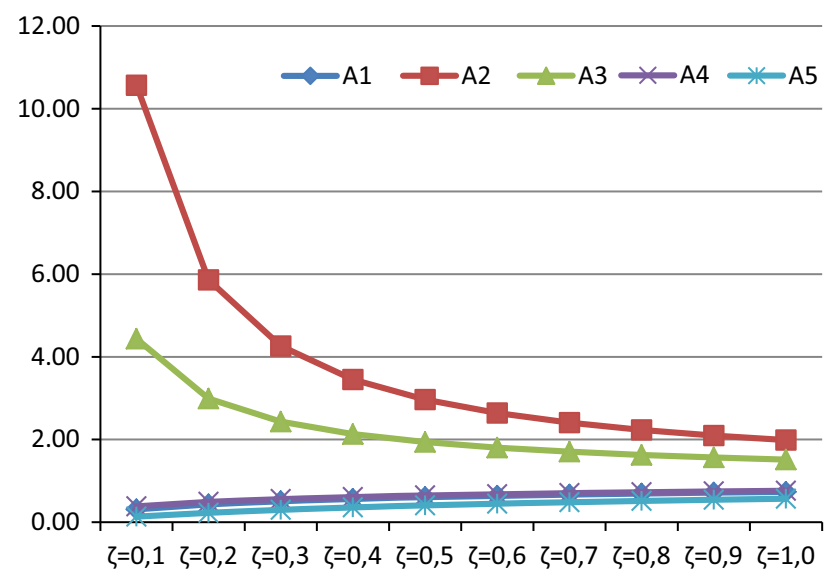

Fig. 2 Variation analysis of $\mathrm{CC}_{i}$ values for each alternative based on Hamming distance

energy policy and wind production site. VIKOR finds out the compromise ranking list, the compromise solution. It ranks and selects best alternative from a set of alternatives in the presence of conflicting attributes. Consider the ranking results yielded by Kaya and Kahraman (2010) and by our proposed method. $A_{2}$ is the greenest 3PL with respect to six green criteria. Because the two approaches yielded the identical ranking results, it could once again confirm that the proposed methods are effective to deal with the problem of personnel selection problem. On the other hand, the Spearman rank correlation coefficient is applied to measure the correlation between fuzzy VIKOR (Kaya and Kahraman 2010) and fuzzy TOPSIS (Chen 2000). Spearman rank correlation coefficient is a nonparametric measure of statistical dependence between two method's results. It evaluates how well the relationship between two method's results and a perfect Spearman correlation must be equal to 1 or -1 . The correlation coefficient between the proposed method, fuzzy TOPSIS and fuzzy VIKOR is high, positive and negative, respectively, as should be.

\section{Conclusion}

Increased environmental pollution is forcing companies to become more environmentally friendly. Companies that produce logistics services should obtain sensitivity to environmental awareness and environmentally friendly policies. The interaction of 3PLs with the environment is much more than the other companies, so that these companies should make further efforts in order to protect it.

In this study, a fuzzy MCDM method is presented combining fuzzy TOPSIS and GRA methods, based on different separation measures, in order to evaluate and select the greenest 3PL. First, the criteria that make 3PLs more "green" are determined as: cooperation with customer company and its customer, green government regulations, environmental management system, green process design, reduction in energy consumption and green network design. The criteria weights based on expert opinions are determined by fuzzy AHP. Then, the proposed combined fuzzy TOPSIS-GRA method is used to evaluate green 3PLs based on different separation measures. Five Turkish 3PLs serve in Istanbul are selected in order to apply a case study to show applicability of the proposed method. The proposed method is verified with respect to different resolving coefficient values and separation 
Table $7 \mathrm{CC}_{i}$ values based on each resolving coefficient for different separation measures

\begin{tabular}{|c|c|c|c|c|c|c|c|c|c|c|c|c|}
\hline & $d_{1}$ & $d_{2}$ & $d_{\mathrm{h}}$ & $l_{1}$ & $l_{2}$ & $l_{\mathrm{h}}$ & $e_{1}$ & $e_{2}$ & $e_{\mathrm{h}}$ & $q_{1}$ & $q_{2}$ & $q_{\mathrm{h}}$ \\
\hline \multicolumn{13}{|c|}{$\zeta=0.1$} \\
\hline$A_{1}$ & 0.31 & 0.32 & 0.32 & 0.31 & 0.32 & 0.32 & 0.32 & 1.16 & 0.32 & 0.32 & 1.16 & 0.32 \\
\hline$A_{2}$ & 10.57 & 10.68 & 10.45 & 10.57 & 10.68 & 10.45 & 10.33 & 1.61 & 10.63 & 10.33 & 1.61 & 10.63 \\
\hline$A_{3}$ & 4.44 & 4.39 & 4.51 & 4.44 & 4.39 & 4.51 & 4.50 & 1.52 & 4.60 & 4.50 & 1.52 & 4.60 \\
\hline$A_{4}$ & 0.38 & 0.39 & 0.39 & 0.38 & 0.39 & 0.39 & 0.40 & 1.09 & 0.41 & 0.40 & 1.09 & 0.41 \\
\hline$A_{5}$ & 0.14 & 0.14 & 0.14 & 0.14 & 0.14 & 0.14 & 0.14 & 0.86 & 0.14 & 0.14 & 0.86 & 0.14 \\
\hline \multicolumn{13}{|c|}{$\zeta=0.2$} \\
\hline$A_{1}$ & 0.43 & 0.44 & 0.44 & 0.43 & 0.44 & 0.44 & 0.44 & 1.17 & 0.44 & 0.44 & 1.17 & 0.44 \\
\hline$A_{2}$ & 5.86 & 5.90 & 5.82 & 5.86 & 5.90 & 5.82 & 5.76 & 1.53 & 5.86 & 5.76 & 1.53 & 5.86 \\
\hline$A_{3}$ & 2.99 & 2.97 & 3.03 & 2.99 & 2.97 & 3.03 & 3.04 & 1.45 & 3.05 & 3.04 & 1.45 & 3.05 \\
\hline$A_{4}$ & 0.49 & 0.49 & 0.50 & 0.49 & 0.49 & 0.50 & 0.51 & 1.06 & 0.51 & 0.51 & 1.06 & 0.51 \\
\hline$A_{5}$ & 0.23 & 0.23 & 0.23 & 0.23 & 0.23 & 0.23 & 0.23 & 0.87 & 0.23 & 0.23 & 0.87 & 0.23 \\
\hline \multicolumn{13}{|c|}{$\zeta=0.3$} \\
\hline$A_{1}$ & 0.51 & 0.51 & 0.51 & 0.51 & 0.51 & 0.51 & 0.51 & 1.16 & 0.51 & 0.51 & 1.16 & 0.51 \\
\hline $\mathrm{A}_{2}$ & 4.26 & 4.28 & 4.23 & 4.26 & 4.28 & 4.23 & 4.20 & 1.46 & 4.26 & 4.20 & 1.46 & 4.26 \\
\hline$A_{3}$ & 2.43 & 2.42 & 2.46 & 2.43 & 2.42 & 2.46 & 2.47 & 1.40 & 2.47 & 2.47 & 1.40 & 2.47 \\
\hline$A_{4}$ & 0.56 & 0.56 & 0.56 & 0.56 & 0.56 & 0.56 & 0.58 & 1.05 & 0.57 & 0.58 & 1.05 & 0.57 \\
\hline$A_{5}$ & 0.30 & 0.30 & 0.30 & 0.30 & 0.30 & 0.30 & 0.30 & 0.88 & 0.31 & 0.30 & 0.88 & 0.31 \\
\hline \multicolumn{13}{|c|}{$\zeta=0.4$} \\
\hline$A_{1}$ & 0.57 & 0.57 & 0.57 & 0.57 & 0.57 & 0.57 & 0.57 & 1.15 & 0.57 & 0.57 & 1.15 & 0.57 \\
\hline$A_{2}$ & 3.45 & 3.47 & 3.44 & 3.45 & 3.47 & 3.44 & 3.41 & 1.41 & 3.45 & 3.41 & 1.41 & 3.45 \\
\hline$A_{3}$ & 2.13 & 2.12 & 2.15 & 2.13 & 2.12 & 2.15 & 2.17 & 1.35 & 2.16 & 2.17 & 1.35 & 2.16 \\
\hline$A_{4}$ & 0.61 & 0.61 & 0.61 & 0.61 & 0.61 & 0.61 & 0.62 & 1.04 & 0.62 & 0.62 & 1.04 & 0.62 \\
\hline$A_{5}$ & 0.36 & 0.36 & 0.36 & 0.36 & 0.36 & 0.36 & 0.36 & 0.89 & 0.36 & 0.36 & 0.89 & 0.36 \\
\hline \multicolumn{13}{|c|}{$\zeta=0.5$} \\
\hline$A_{1}$ & 0.61 & 0.61 & 0.61 & 0.61 & 0.61 & 0.61 & 0.61 & 1.14 & 0.61 & 0.61 & 1.14 & 0.61 \\
\hline$A_{2}$ & 2.97 & 2.98 & 2.95 & 2.97 & 2.98 & 2.95 & 2.94 & 1.37 & 2.97 & 2.94 & 1.37 & 2.97 \\
\hline$A_{3}$ & 1.94 & 1.93 & 1.96 & 1.94 & 1.93 & 1.96 & 1.97 & 1.32 & 1.96 & 1.97 & 1.32 & 1.96 \\
\hline$A_{4}$ & 0.65 & 0.65 & 0.65 & 0.65 & 0.65 & 0.65 & 0.66 & 1.03 & 0.66 & 0.66 & 1.03 & 0.66 \\
\hline$A_{5}$ & 0.41 & 0.41 & 0.41 & 0.41 & 0.41 & 0.41 & 0.41 & 0.90 & 0.41 & 0.41 & 0.90 & 0.41 \\
\hline \multicolumn{13}{|c|}{$\zeta=0.6$} \\
\hline$A_{1}$ & 0.64 & 0.64 & 0.64 & 0.64 & 0.64 & 0.64 & 0.64 & 1.13 & 0.65 & 0.64 & 1.13 & 0.65 \\
\hline$A_{2}$ & 2.64 & 2.65 & 2.63 & 2.64 & 2.65 & 2.63 & 2.62 & 1.34 & 2.64 & 2.62 & 1.34 & 2.64 \\
\hline$A_{3}$ & 1.80 & 1.80 & 1.82 & 1.80 & 1.80 & 1.82 & 1.83 & 1.29 & 1.82 & 1.83 & 1.29 & 1.82 \\
\hline$A_{4}$ & 0.68 & 0.68 & 0.68 & 0.68 & 0.68 & 0.68 & 0.69 & 1.02 & 0.69 & 0.69 & 1.02 & 0.69 \\
\hline$A_{5}$ & 0.45 & 0.45 & 0.45 & 0.45 & 0.45 & 0.45 & 0.45 & 0.91 & 0.45 & 0.45 & 0.91 & 0.45 \\
\hline \multicolumn{13}{|c|}{$\zeta=0.7$} \\
\hline$A_{1}$ & 0.67 & 0.67 & 0.67 & 0.67 & 0.67 & 0.67 & 0.67 & 1.13 & 0.67 & 0.67 & 1.13 & 0.67 \\
\hline$A_{2}$ & 2.41 & 2.42 & 2.40 & 2.41 & 2.42 & 2.40 & 2.39 & 1.31 & 2.41 & 2.39 & 1.31 & 2.41 \\
\hline$A_{3}$ & 1.71 & 1.70 & 1.72 & 1.71 & 1.70 & 1.72 & 1.73 & 1.27 & 1.72 & 1.73 & 1.27 & 1.72 \\
\hline$A_{4}$ & 0.70 & 0.70 & 0.71 & 0.70 & 0.70 & 0.71 & 0.71 & 1.02 & 0.71 & 0.71 & 1.02 & 0.71 \\
\hline$A_{5}$ & 0.49 & 0.49 & 0.49 & 0.49 & 0.49 & 0.49 & 0.49 & 0.91 & 0.49 & 0.49 & 0.91 & 0.49 \\
\hline \multicolumn{13}{|c|}{$\zeta=0.8$} \\
\hline$A_{1}$ & 0.69 & 0.70 & 0.69 & 0.69 & 0.70 & 0.69 & 0.70 & 1.12 & 0.70 & 0.70 & 1.12 & 0.70 \\
\hline$A_{2}$ & 2.23 & 2.24 & 2.23 & 2.23 & 2.24 & 2.23 & 2.22 & 1.29 & 2.23 & 2.22 & 1.29 & 2.23 \\
\hline$A_{3}$ & 1.63 & 1.62 & 1.64 & 1.63 & 1.62 & 1.64 & 1.65 & 1.25 & 1.64 & 1.65 & 1.25 & 1.64 \\
\hline$A_{4}$ & 0.73 & 0.72 & 0.73 & 0.73 & 0.72 & 0.73 & 0.73 & 1.02 & 0.73 & 0.73 & 1.02 & 0.73 \\
\hline$A_{5}$ & 0.52 & 0.52 & 0.52 & 0.52 & 0.52 & 0.52 & 0.52 & 0.92 & 0.52 & 0.52 & 0.92 & 0.52 \\
\hline
\end{tabular}


Table 7 continued

\begin{tabular}{|c|c|c|c|c|c|c|c|c|c|c|c|c|}
\hline & $d_{1}$ & $d_{2}$ & $d_{\mathrm{h}}$ & $l_{1}$ & $l_{2}$ & $l_{\mathrm{h}}$ & $e_{1}$ & $e_{2}$ & $e_{\mathrm{h}}$ & $q_{1}$ & $q_{2}$ & $q_{\mathrm{h}}$ \\
\hline \multicolumn{13}{|c|}{$\zeta=0.9$} \\
\hline$A_{1}$ & 0.71 & 0.72 & 0.72 & 0.71 & 0.72 & 0.72 & 0.72 & 1.11 & 0.72 & 0.72 & 1.11 & 0.72 \\
\hline$A_{2}$ & 2.10 & 2.10 & 2.09 & 2.10 & 2.10 & 2.09 & 2.08 & 1.27 & 2.10 & 2.08 & 1.27 & 2.10 \\
\hline$A_{3}$ & 1.57 & 1.56 & 1.58 & 1.57 & 1.56 & 1.58 & 1.58 & 1.23 & 1.58 & 1.58 & 1.23 & 1.58 \\
\hline$A_{4}$ & 0.74 & 0.74 & 0.75 & 0.74 & 0.74 & 0.75 & 0.75 & 1.02 & 0.75 & 0.75 & 1.02 & 0.75 \\
\hline$A_{5}$ & 0.54 & 0.55 & 0.54 & 0.54 & 0.55 & 0.54 & 0.55 & 0.92 & 0.55 & 0.55 & 0.92 & 0.55 \\
\hline \multicolumn{13}{|c|}{$\zeta=1.0$} \\
\hline$A_{1}$ & 0.73 & 0.73 & 0.73 & 0.73 & 0.73 & 0.73 & 0.73 & 1.11 & 0.74 & 0.73 & 1.11 & 0.74 \\
\hline$A_{2}$ & 1.99 & 1.99 & 1.98 & 1.99 & 1.99 & 1.98 & 1.97 & 1.25 & 1.99 & 1.97 & 1.25 & 1.99 \\
\hline$A_{3}$ & 1.52 & 1.51 & 1.52 & 1.52 & 1.51 & 1.52 & 1.53 & 1.22 & 1.53 & 1.53 & 1.22 & 1.53 \\
\hline$A_{4}$ & 0.76 & 0.76 & 0.76 & 0.76 & 0.76 & 0.76 & 0.77 & 1.01 & 0.77 & 0.77 & 1.01 & 0.77 \\
\hline$A_{5}$ & 0.57 & 0.57 & 0.57 & 0.57 & 0.57 & 0.57 & 0.57 & 0.92 & 0.57 & 0.57 & 0.92 & 0.57 \\
\hline
\end{tabular}

Table 8 Ranking results of fuzzy TOPSIS, fuzzy VIKOR and the proposed method

\begin{tabular}{lllllll}
\hline & $\begin{array}{l}\text { Fuzzy TOPSIS } \\
\text { (Chen 2000) }\end{array}$ & Rank & $\begin{array}{l}\text { Fuzzy VIKOR (Kaya } \\
\text { and Kahraman 2010) }\end{array}$ & Rank & $\begin{array}{l}\text { The proposed method (Burillo and } \\
\text { Bustince's Hamming distance) }\end{array}$ & Rank \\
\hline$A_{1}$ & 0.1642 & 3 & 0.5900 & 3 & 0.6078 & 3 \\
$A_{2}$ & 0.2263 & 1 & 0.0000 & 1 & 2.9659 & 1 \\
$A_{3}$ & 0.2069 & 2 & 0.2024 & 2 & 1.9397 & 2 \\
$A_{4}$ & 0.1477 & 4 & 0.7313 & 4 & 0.6481 & 4 \\
$A_{5}$ & 0.1147 & 5 & 1.0000 & 5 & 0.4073 & 5 \\
\hline
\end{tabular}

measures and also compared with fuzzy TOPSIS and fuzzy VIKOR method results. As future directions, different MCDM methods can be applied and compared to check validity of our results. The proposed method can be applied to 3PLs in other countries.

\section{References}

Ageron B, Gunasekaran A, Spalanzani A (2011) Sustainable supply management: an empirical study. Int J Prod Econ 150(1):168-182

Aghazadeh SM (2003) How to choose an effective third party logistics provider. Manag Res News 2(7):50-58

Amindoust A, Ahmed S, Saghafinia A, Bahreininejad A (2012) Sustainable supplier selection: a ranking model based on fuzzy inference system. Appl Soft Comput 12:1668-1677

Awasthi A, Chauhan SS, Goyal SK (2010) A fuzzy multicriteria approach for evaluating environmental performance of suppliers. Int J Prod Econ 126(2):370-378

Azadi M, Saen RF (2011) A new chance-constrained data envelopment analysis for selecting third-party reverse logistics providers in the existence of dual-role factors. Expert Syst Appl 38:12231-12236

Bhatnagar R, Sohal AS, Millen R (1999) Third party logistics services: a Singapore perspective. Int J Phys Distrib Logist Manag 29:569-587

Buckley JJ (1985) Fuzzy hierarchical analysis. Fuzzy Set Syst $17: 233-247$
Burillo P, Bustince H (1996) Entropy on intuitionistic fuzzy sets and interval-valued fuzzy sets. Fuzzy Set Syst 78:305-316

Buyukozkan G (2012) An integrated fuzzy multi-criteria group decision-making approach for green supplier evaluation. Int $\mathrm{J}$ Prod Res 50(11):2892-2909

Buyukozkan G, Ciftci G (2012) A novel hybrid MCDM approach based on fuzzy DEMATEL, fuzzy ANP and fuzzy TOPSIS to evaluate green suppliers. Expert Syst Appl 39:3000-3011

Chen CT (2000) Extensions of the TOPSIS for group decisionmaking under fuzzy environment. Fuzzy Set Syst 114:1-9

Chen CC (2009) Environmental impact assessment framework by integrating scientific analysis and subjective perception. Int $\mathrm{J}$ Environ Sci Technol 6(4):605-618

Chen SJ, Hwang CL (1992) Fuzzy multi attribute decision making. Lecture notes in economics and mathematical system series, vol 375. Springer, New York

Chen MF, Tzeng GH (2004) Combining grey relation and TOPSIS concepts for selecting an expatriate host country. Math Comput Model 40(13):1473-1490

Deng JL (1982) Control problems of grey systems. Syst Control Lett $1(5): 288-294$

Deng JL (1989) Introduction to grey system theory. J Grey Syst $1: 1-24$

Eglese R, Black D (2010) Optimizing the routing of vehicles. In: McKinnon A, Culliane S, Browne M, Whiteing A (eds) Green logistics: improving the environmental sustainability of logistics. Kogan Page Publishers, London

Erdogan M, Gumus AT (2012) Environmental consciousness of 3PL firms: a brief literature review. In: Proceeding of the international conference on IT applications and management, İstanbul, June 2012, pp 194-200 
Evangelista P, Huge-Brodin M, Isaksson K, Sweeney E (2011) The impact of 3PL's green initiatives on the purchasing of transport and logistics services: an exploratory study. In: Proceedings of the 20th International Purchasing and Supply Education and Research Association (IPSERA) conference

Fu X, Zhu Q, Sarkis J (2012) Evaluating green supplier development programs at a telecommunications systems provider. Int J Prod Econ 140(1):357-367

Govindan K, Palaniappan M, Zhu Q, Kannan D (2012) Analysis of third party reverse logistics provider using interpretive structural modeling. Int J Prod Econ 140(1):204-211

Grzegorzewski P (2004) Distance between intuitionistic fuzzy sets and/or interval-valued fuzzy sets on the Hausdorff metric. Fuzzy Set Syst 148:319-328

Gumus AT (2009) Evaluation of hazardous waste transportation firms by using a two step fuzzy-AHP and TOPSIS methodology. Expert Syst Appl 36:4067-4074

Hamdan A, Rogers KJ (2008) Evaluating the efficiency of 3PL logistics operations. Int J Prod Econ 113:235-244

Handfield R, Walton R, Sroufe R, Melnky SA (2002) Applying environmental criteria to supplier assessment: a study in the application of the analytical hierarchy process. Eur J Oper Res 141:70-87

Harris I, Rodrigues SV, Naim M, Mumford C (2010) Restructuring of logistics systems and supply chains. In: McKinnon A, Culliane S, Browne M, Whiteing A (eds) Green Logistics: improving the environmental sustainability of logistics. Kogan Page Publishers, London

Ho W, He T, Man Lee CK, Emrouznejad A (2012) Strategic logistics outsourcing: an integrated QFD and fuzzy AHP approach. Expert Syst Appl 3:10841-10850

Humphreys PK, Wong YK, Chan FTS (2003) Integrating environmental criteria into the supplier selection process. J Mater Process Technol 138:349-356

Hwang CL, Yoon K (1992) Fuzzy multiple attribute decision making: theory and application. Springer, Berlin

Işıklar G, Alptekin E, Büyüközkan G (2007) Application of a hybrid intelligent decision support model in logistics outsourcing. Comput Oper Res 34:3701-3714

Jharkharia S, Shankar R (2007) Selection of logistics service provider: an analytic network process (ANP) approach. Omega 35:274-289

Kannan G, Pokharel S, Kumar PS (2009) A hybrid approach using ISM and fuzzy TOPSIS for the selection of reverse logistics provider. Resour Conserv Recycl 54:28-36

Kaya T, Kahraman C (2010) Multicriteria renewable energy planning using an integrated fuzzy VIKOR \& AHP methodology: the case of Istanbul. Energy 35(6):2517-2527

Krumwiede DW, Sheu C (2002) A model for reverse logistics entry by third-party providers. Omega 30:325-333

Kuo RJ, Wang YC, Tien FC (2010) Integration of artificial neural network and MADA methods for green supplier selection. J Clean Prod 18(12):1161-1170

Kuo RJ, Hsu CW, Chen YL (2015) Integration of fuzzy ANP and fuzzy TOPSIS for evaluating carbon performance of suppliers. Int J Environ Sci Technol. doi:10.1007/s13762-015-0819-9

Lai K, Christina WYW (2012) Green logistics management and performance: some empirical evidence from Chinese manufacturing exporters. Omega 40:267-282

Lee AHI, Kang Y, Hsu HCF, Hung HC (2009) A green supplier selection model for high-tech industry. Expert Syst Appl 36:7917-7927

Lieb K, Lieb R (2010) Environmental sustainability in the third-party logistics (3PL) industry. Int $\mathrm{J}$ Phys Distrib Logist Manag 40:524-533
Liu H, Wang W (2009) An integrated fuzzy approach for provider evaluation and selection in third-party logistics. Expert Syst Appl 36:4387-4398

McKinnon A (2010a) Product-level carbon auditing of supply chains, environmental imperative or wasteful distraction? Int J Phys Distrib Logist Manag 40:42-60

McKinnon A (2010b) Environmental sustainability: a new priority for logistics managers. In: McKinnon A, Culliane S, Browne M, Whiteing A (eds) Green logistics: improving the environmental sustainability of logistics. Kogan Page Publishers, London

McKinnon A (2010c) Increasing fuel efficiency in the road freight sector. In: McKinnon A, Culliane S, Browne M, Whiteing A (eds) Green logistics: improving the environmental sustainability of logistics. Kogan Page Publishers, London

Min H, Ko H (2008) The dynamic design of a reverse logistics network from the perspective of third-party logistics service providers. Int J Prod Econ 113:176-192

Murphy P, Poist RF, Braunschweig CD (1994) Management of environmental issues in logistics: current status and future potential. Transp J 34:48-56

Noci G (1997) Designing green vendor rating systems for the assessment of a supplier's environmental performance. Eur J Purch Supply Manag 3(2):103-114

Park JH, Lim KM, Park JS, Kwun YC (2008) Distances between interval-valued intuitionistic fuzzy sets. J Phys: Conf Ser 96(012089): $1-8$

Park JH, Cho HJ, Kwun YC (2011a) Extension of the VIKOR method for group decision making with interval-valued intuitionistic fuzzy information. Fuzzy Optim Decis Mak 10:233-253

Park JH, Park YII, Kwun YC, Tan X (2011b) Extension of the TOPSIS method for decision making problems under intervalvalued intuitionistic fuzzy environment. Appl Math Model 35:2544-2556

Ramanathan R, Yunfeng J (2009) Incorporating cost and environmental factors in quality function deployment using data development analysis. Omega 37:711-723

Razzaque MA, Sheng C (1998) Outsourcing of logistics functions: a literature survey. Int J Phys Distrib Logist Manag 28:89-107

Robertson PW, Gibson PR, Flanagan JT (2002) Strategic supply chain development by integration of key global logistical process linkages. Int J Prod Res 40:4021-4040

Rodrigue J, Slack B, Comtois C (2001) Green logistics (The paradoxes of). The handbook of logistics and supply-chain management. Handbooks in transport \#2. Pergamon/Elsevier, London

Shan L (2012) Research on green logistics service providers selection based on intuitionistic language fuzzy entropy. J Comput 7:540-546

Tezuka K (2011) Rationale for utilizing 3PL in supply chain management: a shippers' economic perspective. IATSS Res $35: 24-29$

Tseng ML (2010) Using linguistic preferences and grey relational analysis to evaluate the environmental knowledge management capacity. Expert Syst Appl 37:70-81

Tuzkaya G, Ozgen A, Ozgen D, Tuzkaya UR (2009) Environmental performance evaluation of suppliers: a hybrid fuzzy multicriteria decision approach. Int $\mathbf{J}$ Environ Sci Technol 6(3):477-490

Viswanathan N (2009) Supply chain network design: architecting a green future. www.supplychainbrain.com/content/home/singlearticle-page/article/supply-chain-network-design-architecting-agreen-future. $15 \mathrm{Jul} 2012$

Walker H, Sisto LD, McBain D (2008) Drivers and barriers to environmental supply chain management practices: lessons from the public and private sectors. J Purch Supply Manag 14:69-85 
Walton SV, Handfield RB, Melnyk SA (1998) The green supply chain: integrating. suppliers into environmental management processes. J Supply Chain Manag 34(2):2-11

Wang YJ (2009) Combining grey relation analysis with FMCGDM to evaluate financial performance of Taiwan container lines. Expert Syst Appl 36:2424-2432

Wei GW (2010) GRA method for multiple attribute decision making with incomplete weight information in intuitionistic fuzzy setting. Knowl-Based Syst 23:243-247
Yang Y, Wu L (2007) Grey entropy method for green supplier selection. In: International conference on wireless communications, networking and mobile computing, pp 4682-4685

Ying J, Li-junb Z (2008) Study on green supply chain management based on circular economy. Mech Mater 84-85:761-764

Zhang SF, Liu SY (2011) A GRA-based intuitionistic fuzzy multicriteria group decision making method for personnel selection. Expert Syst Appl 38:11401-11405 